\title{
Practical Magic Religious of the Pastors and Maestro's Fetish in Congolese Football
}

\author{
Magema Joachim ${ }^{1,2 *}$, Loufoua Lemay Emile Didier ${ }^{3}$, Litotopambou Lucien', Ntinu Kivuvu Baudouin ${ }^{4}$ \\ ${ }^{1}$ Laboratory of Sport Sociology, Higher Institute of Physical Education and Sport, Marien Ngouabi University, Brazzaville, Congo \\ ${ }^{2}$ Direction of Research, Documentation and the Files, National Institute of Youth and Sports (INJS), Brazzaville, Congo \\ ${ }^{3}$ Interdisciplinary Laboratory “Society, Sport, Health, Development” (L3SD), Marien Ngouabi University, Brazzaville, Congo \\ ${ }^{4}$ Department of Physical Education, National Teaching University, Kinshasa, Congo \\ Email: ^majo.mizon@gmail.com
}

How to cite this paper: Joachim, M., Didier, L. L. E., Lucien, L., \& Baudouin, N. K. (2016). Practical Magic Religious of the Pastors and Maestro's Fetish in Congolese Football. Advances in Applied Sociology, 6, 389-399.

http://dx.doi.org/10.4236/aasoci.2016.612029

Received: November 3, 2016

Accepted: December 5, 2016

Published: December 8, 2016

Copyright $\odot 2016$ by authors and Scientific Research Publishing Inc. This work is licensed under the Creative Commons Attribution International License (CC BY 4.0).

http://creativecommons.org/licenses/by/4.0/

\begin{abstract}
The purpose of this study is to apprehend the magic religious practices which emanate from pastors and maestro's fetish and which integrates and invests the mechanisms of sporting management to football. This investigation was articulated around the various phases which characterized the action of pastors and maestro's fetish with an aim attributing victory with the club solicitant. Thus, a cross-sectional anthropological investigation was conducted undertaken from October 2015 to June 2016. It was based on participating observation. The sampling comprised 190 subjects which are 90 leaders of football teams, 20 maestro's fetish, 50 heads of family, clans and notables and 30 circumstantial advisors. These different actors of Congolese football were volunteers to participate in this study. The variables were representations and magic religious practices of pastors and maestro's fetish for their activities in football. The results indicate seven phases of intervention of different actors studied: consultation; engagement of process to aim prediction; prediction of restoration of results born of vision; instruction of pastors and maestro's fetish to the consultant; implementation of the instructions; application of instructions; rescue of consultant. Generally, two objectives characterizing all these phases bias two fundamental situations: 1) to know the score before the unfolding of the competition; 2) to safeguard the results if they are good or to forget the bad scores. These magic religious practices are activities answering expression of habitus. In conclusion, the magic religious beliefs provide in representations of actors as function as habitus, hidden in the collective unconscious memory.
\end{abstract}

\section{Keywords}

Football, Magic Religious Practice, Pastor, Maestro's Fetish, Congo 


\section{Introduction}

Prayer and fetish (nkisi in local language) occupy a place of choice within the clubs of Congolese football from colonial period to our days. With regard to the prayer, it is found mainly at the practice gathered around Roman Catholic Church, Evangelic Church of Congo, Lutheran Church, Salvatory Army. However, traditional churches (Kimbanguism, Lassysm, Matsouanism, Ngunzism, Bundu Dia Kongo) are supposed to intercede near God by their prayers (Kinata, 2002). As for fetish, it is frequent in the traditional societies where the penetration of the preceding churches is proved to be difficult, until our days (Balandier, 1965; Stark \& Bainbridge, 1996). In the case of football, it is nowadays observed an interrelationship between religious and/or magic practices and performance of sport, particularly in football. This observation is also raised by Oumarou and Chazaud (2010) in sub-Saharan Black Africa. Within this framework, the trainer constitutes a relay between pastor and wizard so much so that the victory, at the time of a sporting meeting, is rather allotted to maestro's fetish, with pastor and with the service of players and know-how of trainer. Nature and bad quality of sports infrastructures of football are not also viewed as explanatory factors of low performances of Congolese football at the even-regional or sub-regional level. Indeed, the drives proceed in mud, dust or on a surface not delimited inside the stages of fortune. This process proves with sufficiency that there is a real continuity between the past (the tradition) and the present (the Western modernity conveyed by school and medias). In this context, a socio-economic reality in sub-Saharan countries doesn't allow to be the height stakes of the modern football for competing, with equal play, with the Western countries. Moreover, with an aim of "performer" the clubs of Congo Brazzaville add to their football another element associated to culture and customs: traditional and/or contemporary magic religious practices. Those integrate or invest the mechanisms of sport management.

Pastor or maestro's fetish intervenes in aforementioned mechanism by means of prayer or fetish, thus mingling "African mind" with "Western mind"; i.e. irrational in contrast to rational mind. However, these two logics seem to contribute to the same aim: to gain a match. However, several studies showed that the managers of the Congolese sports structures and, perhaps, all those of the Black Africa, oscillate between the diurnal and night sides (Oumarou \& Chazaud, 2010). For the latter, the even cultural reference frame symbolic system is to be sought side of the religious practices and/or magic a long time present in the vital activities in traditional medium (Mac Gaffey, 1977). The reasons of the survival of those, their implication and their perenities in the activities of football, once included/understood, are supposed to allow the foreign managers in service in Congo and in other countries of Africa to reconcile the rational mind (diurnal side noted in public) and irrational mind (night side).

Our preceding studies relating to the religious practices (Magema, 2013) showed that nearly three or quarters among $75 \%$ of actors of football in Congo Brazzaville request the assistance of God. Their mode of request is sign of the cross, prayer, reading of psalms and praises. If the first three modes of requests are snuffed by leaders, supporters and players, in contrast players made use to praises. The solici- 
tants of no lineage ancestors are consisted to leaders, players and supporters in phase with its social and cultural environment (Medjad, 2006). As for the actors who make recourse to lineage ancestors, they are the players and the referees. In addition, the mode of request of lineage and no lineage ancestors also summarize with prayers for the leaders. The reasons for recourse to divinities by the actors of football initially remain the victory. The second evocation of the leaders and players is linked to protection against adversaries' fetish. All things considered, beyond the beliefs in the gods in the actors of Congolese football, it is all the problems of the religious practices in the development of the sport which is posed. It thus proves necessary to have judicious and adequate strategies to put at the foreground the modern methods of sporting drive to instigate football in Congo- Braz-zaville. Study of Loufoua-Lemay et al. (2016), carried out on the strictly magic level, showed ultimately that actors of Congolese football practice or resort to four categories of fetish according to their capacity or supposed capacity: reinforcing of physical capacities; fetish of protection; perception of the false images and them is leading words; generating natural phenomena, which would cause for example, a rain, an excessive heat, a wind. The same study emphasizes that certain magic acts would be also the work of the totems. Thus, each totem hereafter would exert various roles: 1) totem of the monkey, for force and agility (specificity of the guards); 2) totem of the chameleon, considerate by player like fellow-member between opponents; 3) totem of electric fish (Tsoûla, in local language), release of an electric discharge to the detriment of opponents; 4) totem of catfish, for crossing between attackers with the balloon or between several defensive players; 5) totem elephant, for reduction of space empties posts. To this end, the testimony of a player stipulates that it is at the time when it armed his shooting that football player "see" pachyderm; 6) totem of a sheet of tree (not revealed), for invisibility of attacker in the unfavourable penalty area. However, these totems can be mounted in fetish when one utilizes sympathetic magic. Thus, the actors of Congolese football judge effectiveness of fetish according to the effect or the natural phenomena that they produce. Also, fetish is considered to be effective when realities of the match are in conformity with predictions of maestro's fetish. However, the actors of football express reservations against fetish. However, can one allow himself to think that the activities of trainer and those of maestro's fetish were complementariness?

The study of the magic practices chocolate enlighten and their implication with football with an aim of generating a sporting performance cannot be undertaken, in our opinion, that while making use of the social sciences (Laman, 2000), particularly in social anthropology and cultural. Such is the proof of sociological way borrowed to analyze the implication of the magic practices for enlighten Congolese football performance.

Our study is articulated around the various phases which characterize the action of pastor and maestro's fetish for victory of a club at the time of a competition. Assumption of this study is thus drawing up: petitioners aspire to gifts, practices and prophesies of the pastors and maestro's fetish, supposed to control the spirits success by simple 
habitus. The aim of this study is to update the various phases from ritual used by the pastors or maestro's fetish during the consultations.

\section{Methods}

\subsection{Topics}

This anthropological and prospective study was carried out in the various departments of Congo from October 2015 to June 2016 related to the pastors and maestro's fetish which intervenes within the clubs of federal football. It was a question of apprehending the practices of pastors and maestro's fetish then consultations by the sporting actors. Those were followed by means of a participating observation at the time of their phases of consultation. For this reason, the approach by participating observation was adopted. The choice of participating observation is explained by the fact that the magic-religious practices studied have not been observed by researchers belonging to the milieu. They did not participate in the phenomenon, studied, which were foreign to them. This method has several advantages. It enables observation to be carried out for observers trained in the requirements of research in the social sciences. This method offers fairly strong guarantees of validity and objectivity because of the distance initially between the search and the phenomenon observed (Spradley, 1980), which limits the risks of interaction. This kind of observation supposes between the observer and this studied phenomenon may be more or less intense more or less prolonged, then the integration of the observer will be deeper and more pronounced and we then speak of a particular observation. This observation justifies the adoption of participant observation in this study. It allowed a thorough taking into account of the magic and religious practices in semi- traditional medium where activities of federal football proceed.

\subsection{Sampling}

Therefore to obtain information likely to satisfy the needs for research, in particular those which consist in determining the reasons of the survival of the magic-chocolate enlighten practices, and their implication in football, we used maintenance. A total of 190 subjects were recruited (Table 1). The selection criteria of 190 investigating members are related to those involved in the search for performance through magic religious

Table 1. Statistics of investigate subjects.

\begin{tabular}{ccc}
\hline Subjects & Effective (n) & Percentage (\%) \\
\hline Leaders of clubs 90 & $47,4^{*}$ \\
Maestro's fetish 20,105 & \\
Heads of family, clan and notable 50,263 & \\
Circumstantial advisors 30,158 & \\
Total 190,100
\end{tabular}

$\left.{ }^{*}\right)$ : significant difference to $5 \%$ according to the test $\mathrm{S}$ of Sokal. 
practices. Most of the Congolese football teams belong to the ethnic groups where the survival of these societies is omnipresent. It was in this context that the criteria for inclusion in the studies were:

- Be a member of the committee responsible for magic religious activities;

- Have recourse to religious and/or magical practices;

- Have taken part in religious and/or magical activities in favor or at the expense of a sports club;

- Be maestro's fetish or pastor engaged in football activities;

- Being notable practicing religious and/or magical activities for the benefit of a football club;

- Fan club members involved in the research of pastors and Nganga Nkissi in the football field.

\subsection{Protocol}

This one had as an orientation qualitative function. However, the conditions of realization of maintenance were chosen by inquired. The duration of this one was about thirty minutes at one hour. All things considered, the use of maintenance was requested according to the need and moments. During the participating observation and maintenance, as of the first contact, the objectives of research, the status of researcher and departmental investigating assistances were known advisors. The data-gathering was based on the active implication of researcher through the observation and the direct participation in the actions carried out by pastors and maestro's fetish. The need for reflecting on significance of any act was integrated into this research like an additional dimension. The data resulting from the semi directing talks were collected by holding account of their structuration: are religious dimension into which the Christian God, product of colonization, the spirits of nature and the ancestors are integrated; a magic dimension in which appear the fetish and totems. The data collected started to pre investigation. At the time of this stage, the quality of the data was determined by the reading of fundamental studies informing about religious and/or magic practices in general, Kongo, Teke and Mbosi particularly. There was some discussion having a minimum of theoretical information and about taking note of some studies in anthropology, but also in the whole of the disciplines which this research challenges. Hearths in which the magic-religious enlighten activities are very active were privileged, within the framework of the formulation of assumptions, construction of problems and starting questions. With regard to the choice of the investigating assistances, ten (10) on the whole were selected at a rate of one per department of the hinterland. The two other close departments, Brazzaville and the Pool, were entirely covered by the researcher. The investigating assistances were selected because of their occupations and by the fact that the already undertook research of Master level at least (Physical Education teachers, actors of the sporting movement in the departments). However, the choice of the investigating assistances took account of requirements as follow: 1) to speak local language about the zones of survey; 2) to establish easy contacts; 3 ) not to leave itself with 
the discourage in relation to refusal; 4) not to obstruct itself to pose questions; 5) not to be afraid of fetish or unmistaken for religious activities; 6) to be receptive, attentive, discreet and neutral. After selection, it was meant to them the mechanisms to follow in the process of communication during maintenance and those related to participating observation. Ultimately, the selection of the investigating assistances was done into three stages: choice; short formation with the general principles of investigation (standardization, confidentiality, project and its objectives, specificity of each question); control (numbers of paid visits, recording of talks). The participating observation was carried out by mutual agreement with the investigating assistances. The making of contact with the advisors, as for it, was done by being of the goal and interest of the study. Once their own interest hung, we had put them in confidence by leading them to collaborate, to answer their legitimate concerns. The investigation didn't only proceed in urban centers where the use of the national languages is possible between interlocutors, but also uncertain villages, in the heart of the departments where the local languages are well understood by the investigating assistances. Being the moments and places of data-gathering, we didn't have, at the beginning, of places determined to carry out our surveys. But those ended up being binding on us. They were the training grounds of the places freely selected by the surveyed subjects. As for the maestro's fetish, the sites where they received the consulting clubs and where they effectuate their practices were privileged for them. The stages where preceded sporting competitions were places of predilection.

However, the moments of maintenance were chosen generally by the advisors themselves.

\subsection{Statistical Analyses}

In order to validate the frequencies obtained during the talks, we carried out a Confirmatory Factorial Analysis (CFA) to confirm the reliability of the various types of answer, technique used in the social investigations in sporting context (Jöreskog \& Sörborn, 1999). For that, we were useful ourselves of Root Mean Square Error of Approximation (RMSEA). This index tests the bad adequacy of the answers during talks. Jöreskog \& Sörborn, (1999) suggest that value of the RMSEA lower than 0.05 is significant of a good reliability, and that a value lower than 0.08 is acceptable. The comparison between more than two percentages (frequencies) of answers was carried out using the S test of Sokal and Rohlf (1995). In addition, we also relied on the statistical index $\chi^{2}$ to analyze the influence of the type of actors surveyed on the answers obtained. The statistical software used was SPSS, version 15.2. The statistical threshold of significance of all the tests was fixed at $5 \%$.

\section{Results}

On the whole, the seven (7) phases enunciated previously were identified in the action of pastor or maestro's fetish in according to team. The phase of consultation of maestro's fetish or pastor of church proceeds according to two synopsis: determination of 
the object of consultation by maestro's fetish or pastor; the consult exposes the object of his presence to maestro's fetish or pastor. Two phases characterize intervention of a priest: before and after the match. Before the match, it exerts its spiritual gifts and predicts the results of reality first of the aforesaid match. If the results are good, a prayer is made to God to reinforce these assets by requiring of him the peace and the protection of the actors of play. This victory interview is apparently the expression of the will of God. If the prediction reflects bad results, a mechanism spiritual should be set in motion for ravish the victory. To this end, angels as Michael Holy considered within the Catholic Church as a very power full combatant of Christian God are requested. Hollies, who were beatified by the various popes, are solicited by means to appeals, to incite them to take share with the various operations aiming at ravish the victory. It appears that the angels or the hearts of the beatified people by a pope would be servants of God whom can act in according to applicants.

Report 1: "When Devil-Blacks' team of Brazzaville, finalist of the Cup of Congo, opposes AC Léopards, team of Dolisie (third city of Congo), during August 2011 at the stadium Massamba-Debat, one catholic priest (song of club Devil-Blacks' team) takes the care to predict score of a goal with zero $(1-0)$ with depends on Devil-Blacks. This score was confirmed on the ground in spite of the three pigeons with the dark plumage that Devil-Blacks released at the beginning of the match. The white pigeon that AC Léopards released in its turn seemed to have been right of the three of Devil-Blacks. After the observation of these facts and during the discussion with an advisor, this last affirmed that the song of Black-Devils team would have", in view of "this score would not change because of the sacrifice of human blood which the team of AC Léopards would have offered".

Supposed the sacrifice of blood seems real to mean a supreme satisfaction with the requirements of the gods, other forms of sacrifice or litanies or offerings would be null. The sacrifice of human blood cannot inflect the will of the gods who receive it nor doesn't allow the gods of the opposing team ravish the victory. These reported facts were not confirmed of Leopards' team, but one of the leaders admitted having gone with others in Democratic Republic of Congo to prepare the match mystically (report with a member of the committee of Black-Devils' team and one of AC Leopards' team, responsible for the magic-religious activities). Once the object of the consultation is known or exposed, maestro's fetish or pastor consults his divinity or her fetish by means of a song or of an oral formulation or of mimicry. The whole is crowned or not offerings. At the priest of pastor, two attitudes were observed: 1) after a prayer of exhortation, pastor either is struck by a crisis of possession, or by a fright. If pastor is surrounded of the members of his directory, one of them embers either is had, or struck of a fright. In this moment, it had or excited communicates briefly and calmly or in an agitated way unfolding of the match (its beginning, its development and its end); 2) the vision or the message perceived following a prayer addressed to a higher reality (divinity) is made available of the consults: pastor communicates what it will have "see" or 
"hear" on behalf of higher reality. During this phase of interlocking of the process of prediction, maestro's fetish adopts them hereafter one of the three postures. Thus for maestro's fetish, fetish is perceived as a partner with whom it developed relations of co-operation having led to the communication automatisms. At others, fetish seems to be object "computerized"; the maestro's fetish adopts an attitude of a man who, having supported a button, waits by listening to the answer which will be transmitted. For two of them, it is used a fetish which is hurry during football field drawn on a shelf out of wooden or a ground.

Report 2: "The members of the consulting club follow a match while looking in a utensils made of clay white and filled with water, it is rectangular form and approximately 50 centimeters of length, 20 centimeters broad and 40 centimeters of depth. In its content, the figure of football field is materialized whose lines are of black color. Over the widths, four stones of which two on each side symbolize the posts. The maestro's fetish hardening a small water-bottle which 20 watery insects on the sheet of water which leaves, at once are devoted to what seems to be a choreography singular: a presence of attack and defense. When one of the insects succeeds in passing in the space located in the trajectory of the posts, this gesture is interpreted like a goal. Thus on the basis of the side allotted to consulting club, score is known of everyone".

Report 3: "the consultants view a singular match in stadium of football drawn on the ground. Twenty pieces of brushwood, drawn from a branch of a palm tree, approximately 8 centimeters length, are placed inserted, on three centimeters approximately, in the ground on both sides of the line of centers. Placed ten on each side, this brushwood symbolizes the twenty players of field. After a request formulated with the fetish (a wood figurine of the size of an ordinary headstock) $t$ hat the maestro's fetishism holds in its hand, the brushwood put themselves moving on all area while being inserted in the ground. These comings and goings of the football players stop temporarily and take again sometime afterwards. This small pause means that there was goal. And only them maestros' fetish designates the team has just marked, because he from the beginning takes the care to allot to the consulting team his camp. Ten to fifteen minutes are enough to designate the winner of the meeting. Here, when gaining it he is the consulting team returns to the maestro's fetish for safeguard the rough result acquired at the time of the singular match. Thus, of the fetish of protection are proposes: the support by the players of a small piece of coal, a stem of brushwood drawn from a branch of a palm tree, a stem of match, etc. These objects are apparently invested by the spirits" (observation of December 2016).

As for the phase of restitution of the facts "see" or "hear", the spirit of the fetish which had just caused the crisis of possession or fright puts to correspond to the reality of the facts. The singularity is that at the end of the restitution, excited does not remember almost more, or partially of what he will have said. 


\section{Discussion}

Our results indicate that the aforementioned restitution can be done by excited person who keeps her clearness, her intelligence, without its memory didn't fail. Here, restoring it seems to be simply "objet" which fetish transmits its testimony (Buakasa, 1973). It fit to note that some maestro's fetish or pastors stop with this phase. For the continuation, they direct the consultant towards one of his par shaving or charisma. With regard to the phase of "manipulation" of the results by pastor or maestro's fetish, two possibilities have observed: 1) the first consists in safe guarding the positive results by a process of protection of the assets. The means is the prayer addressed to God and/or to the Hollies (case of pastor or catholic priest), with the no lineage ancestors (case of a priest of the syncretic church); 2) the second consists in forging the bad results. In this last case, the process is follow: "inflect" will of God by the supplications or to impregnate divine capacity in objects carried by the players (case of a priest or Christian pastor); to be search spirits of nature and the no lineage ancestors or to impregnate a divine capacity on objects carried by the players (case of priests of the syncretic churches); to increase the physical capacities of the players, "vend" goals for to deteriorate physical capacities of the adversaries, to produce natural phenomena aiming at helping the consulting club, to destroy adversaries' fetish, to create false images et to proceed to a sacrifice of blood (case of maestro's fetish). Two situations lived on the ground revealed it.

Situation 1: "A angansengue (head of Akwa ground) in its wanting to put the team of its village safe from a humiliation, because led two goals to zero, calls some with the former heads of ground by their name. Little before the beginning second half-time, it was placed in the center of the ground, reversed the palm wine (tcham-tcham) while requiring of the late heads to erase shame. The second half-time started with a violent wind which blew in direction of the team which led to the score. Thus sat by the players and the wind, the team would have gained boxed six goals".

Situation 2: "In a mystical war which would return the clubs back to back, the purchase of a goal remains an operation indicated and effective. Except if an influence is exerted on the referee to cancel it. The purchase of the goals is a technique which is used when it is about a great match because that is expensive. The required fees are proportional to the interest of the match: cross, qualification, title of champion, etc. In addition, the match is significant plus the fees grow louder and louder. The highest stage is the sacrifice of blood (Tonda, 2005). The presence of a wedge in the organization of the striker or to himself is a symbol very fort: what is acquired by a regular purchase is attribute; in front of as sacrifice of blood, to irreversible situation, the wedge or other objects cannot anything" (Report of Okoyo's maestro's fetish in the department of the Western Basin, January 2016).

During the fifth phase relating to the instruction of maestro's fetish to the consultant, this last is informed on what it must observe like schedules to claim with the victory. The no observance of this ordinance would involve, ipso facto, a defeat. It is with this phase also that are given from the objects devoted to higher realities or the fetish. On the level of the application of the instructions to the consultant, the maestro's fetish or 
the pastors make them obligation disrespected with the letter all the instructions without putting questions and hesitating. The last phase is set in motion when the predicted score and the diagram previous are disturbed by visible or invisible forces of the adversary. The maestro's fetish are mobilized then for "attack": a player on whom rests the chance to mark goals; a referee for the captivate with the detriment of the club adverse; a maestro's fetish of the adverse team by causing a natural phenomenon, etc. this fact announce that this phase can be anticipated before the match by attacking the maestro's fetish of the opposing team particularly.

Ultimately, with football, the work of pastor or maestro's fetish consist of: "read" a match in the invisible; to reinforce the assets when they are the goods results; to "transform" bad results in order to support the victory; to "follow" course of the match so that, if necessary, a regulation or a remediation is made. In the same way, it must help a player or a group of the supporters which estimate to contribute to the victory of its club. Being oneself the players, they are not question for them, to know the exit of a match when they go to maestro's fetish, but to acquire a capacity it leads to be brilliant and marker of goals.

\section{Conclusion}

The magic-religious practices are an activity answering the expression of the habitus, which directs the actor's Congolese foot ballistic in a final direction. Magic-religious practices are social imaginations that reproduce themselves through dialectic between their incorporation and their exteriorization by the social actors in terms of habitus. They continued to express themselves even in the absence of the phenomenon which gave birth to them, that is to say, they would survive even if the conditions had improved.

\section{References}

Balandier, G. (1965). Everyday Life with the Kingdom of Kongo from XVIèto XVIIIè siècle. Paris: Hachette.

Buakasa, T. M. (1973). Unthinkable of Speech. Kindoki and Nkisi in Country Kongo of Zaire. Kinshasa: University Press of Zaire.

Jöreskog, L., \& Sörborn, I. (1999). Lisrel Software for Social Sciences. Bethesda: Myer and Co.

Kinata, C. (2002). In French Congo, Indigenous Priests in Relation to Customs: Case of Area Pool Department (No. 3, pp. 30-35). Brazzaville: Annals of Marien NGOUABI University.

Laman, K. E. (2000). Rays of Truth Followed of Where Darkness Is Dissipated, New Production Carried out in Collaboration with Evangelic Church of Congo. Falkoping: Elanders Gummessons.

Loufoua Lemay, E. D. et al. (2016). Beliefs and Rituals in Congolese Football. Benin Review of Philosophy and Human Sciences, 4, 15-21.

Mac Gaffey, W. (1977). Fetishism Revisited: Kongo "Nkisi” in Sociological Perspective. Africa: Journal of the International African Institute, 42, 140-152.

Magema, J. (2013). Magic Religious Practices and Performance in Congolese Football. Contribution in African Sport Sociology. PhD Thesis of Physical Education, Kinshasa: National Teach- 
ing University.

Mejad, E. (2006). Football Manager.

http://www.frenctouch.org/Lofiversion/index.php/t14602.html

Oumarou, T., \& Chazaud, P. (2010). Football, Religion and Policy in Africa. Sociology of African Football. Paris: Editions L'Harmattan.

Sokal, R. F., \& Rohlf, S. W. (1995). Biometry(7th Edition). San Francisco: Freeman and Co.

Spradley, J. P. (1980). Participant Observation. New York: Holt, Rinehart and Wilson.

Stark, R., \& Bainbridge, W. S. (1996). Theories of Religion. London: Rutgers University Press.

Tonda, J. (2005). The Modern Sovereign. The Body of the Capacity in Central Africa (Congo, Gabon). Paris: Karthala.

Submit or recommend next manuscript to SCIRP and we will provide best service for you:

Accepting pre-submission inquiries through Email, Facebook, LinkedIn, Twitter, etc.

A wide selection of journals (inclusive of 9 subjects, more than 200 journals)

Providing 24-hour high-quality service

User-friendly online submission system

Fair and swift peer-review system

Efficient typesetting and proofreading procedure

Display of the result of downloads and visits, as well as the number of cited articles

Maximum dissemination of your research work

Submit your manuscript at: http://papersubmission.scirp.org/

Or contact aasoci@scirp.org 